\title{
Australian VET Sector - A Critical Evaluation
}

\author{
Stanislaw Paul Maj ${ }^{1}$ \\ ${ }^{1}$ Associate Dean (Research), Engineering Institute of Technology, Western Australia \\ Correspondence: Stanislaw Paul Maj, Associate Dean (Research), Engineering Institute of Technology, 1031 \\ Wellington St., West Perth, 6005. Western Australia. Tel: 1300-138-522. E-mail: paulm@eit.edu.au
}

Received: August 19, 2016

doi:10.5539/mas.v11n1p270
Accepted: October 9, $2016 \quad$ Online Published: December 19, 2016

URL: http://dx.doi.org/10.5539/mas.v11n1p270

\begin{abstract}
The Australian Vocational Education and Training (VET) system is a comprehensive, national framework designed to provide quality outcomes for learners and meet the needs of potential employers. The interdependent checks and balances provide mechanisms for validating quality and relevance. Regular national surveys demonstrate that both students and employers are satisfied with their experience of the VET sector. However, whilst positive feedback is necessary it is not of itself sufficient. In effect it is a false benchmark. To provide best practices in teaching and learning necessitates lecturers having the appropriate skills and underpinning knowledge something that the mandatory Certificate IVE in Training and Assessment does not provide. A more valid benchmark is an objective analysis of the quality using a learning taxonomy such as SOLO. This preliminary analysis of a range of VET courses unequivocally found that course material was well below best practices expectations. However further work is needed.
\end{abstract}

Keywords: VET, training, vocational education

\section{Introduction}

\subsection{Australian VET Sector}

The Australian Vocational Education and Training (VET) system is the basis further education designed to provide work place relevant skills and the associated underpinning knowledge nationally. VET is governed by both government and independent bodies in the context of the National Skills Framework of qualifications. This framework defines the requirements for both the quality and consistency of qualifications and their delivery. An underling principle is the VET sector is informed by industry to ensure relevance to the workplace. The Australian Qualification Framework (AQF) defines all nationally recognized qualifications including VET awards. The AQF provides guidelines for knowledge, skills and their application for all AQF levels from certificate to PhD. The Australian Quality Training Framework (AQTF) is the set of standards and conditions that all providers (private and publically funded) must meet thereby ensuring consistency across the country. To become a registered provider an institution must comply with AQTF essential conditions and standards for initial registration and thereafter AQTF essential conditions and standard for continuing registration. There are three AQTF standards: quality of training and assessment; access and equity and management systems. There are three quality indicators: learner engagement; employer satisfaction and competency completion rate. According to iVET: employer satisfaction focuses on employers' evaluations of learners 'competency development, its relevant to work and further training, and overall quality of the training and assessment; learner engagement focuses on the extent to which learners are engaging in activities likely to promote high-quality skill outcomes; competency completion rate is calculated for qualifications and units of competency delivered (iVET). Only Registered Training Organizations (RTOs) can deliver accredited training, assessment and issue AQT qualifications. The National Training Information Systems (NTIS) is a register of all RTOs. On a broader canvas there are a number of strategic players that include: Council of Australian Governments (COAG); Ministerial Council of Tertiary Education and Employment (MCTEE); National Quality Council; State Training Authorities; Skills Australia; Industry Skills Councils and Industry Training Advisory Bodies (ITABs). Their detailed functions are beyond the scope of this paper. Finally the Australian VET sector is regulated by a range of national, state and territory laws that include: the National Vocational Education and Training Regulator Act 2011 and the Standards for NVR Registered Training Organizations 2011. Again legislative details are beyond the scope of this paper. 


\subsection{Certificate IV in Training and Assessment}

A further requirement, necessary for compliance, is that all staff must have completed the Certificate IV in Training and Assessment (TAE4011). This qualification consists of seven core units:

1. Use training packages and accredited course to meet client needs

2. Design and develop learning programs

3. Plan, organize and deliver group-based learning

4. Plan, organize and facilitate learning in the workplace

5. Plan assessment activities and processes

6. Access competency

7. Participate in assessment validation

In addition to which staff must complete elective units. These are typically:

1. Make a presentation

2. Provide work skill instruction

3. Mentor in the workplace

\subsection{Training Packages}

Training packages are the resources that underpin the VET sector. All training packages must have three compulsory components namely: qualifications i.e. rules that define core and elective units and alignment to the AQF; Units of Competency that define the skills and knowledge to meet relevant regulatory requirements; Assessment Guidelines which define the necessary performance requirements. Training packages are developed by Industry Skills Councils (ISCs) through industry consultation nationally and hence endorsed by the National Quality Council (NQC).

\section{National Evaluation of VET Sector}

Nationally there are nearly 5,000 registered training organizations of which most are private training providers. However the majority of VET students are enrolled in publically-funded providers namely TAFE colleges. According to the Australian Bureau of Statistics in 2008 there were 1.7 million students enrolled in publically funded VET courses (Statistics, 2010). The National Centre for Vocational Education Research (NCVER) is responsible for collecting, managing, analyzing and evaluating statistics about VET. In 2015 over 65,000 students responded to their survey. A selection of the results was as follows:

Employed after training: $74.2 \%$

- $78.8 \%$ found the training relevant to their current job

- $86.7 \%$ were satisfied with the overall quality of their training

In the 2015 survey approximately 9,000 employers across the country were surveyed. A selection of the results is as follows:

- $76.2 \%$ of employers are satisfied that vocational qualifications provide employees with the skills required for their job

- $81.7 \%$ of employers are satisfied that apprentices and trainees receive skills required for their job

- $84.0 \%$ of employers are satisfied that nationally recognized training provides employees with the required skills (NCVER, 2015)

\section{Evaluation}

According to the NCVER 2015 survey the VET sector is a successful national education system with the majority responses being affirmative. However there is evidence that these claims cannot be substantiated from the point of view of pedagogical quality.

\subsection{TAE}

The Certificate IV in Training and Assessment (TAE4011) is the qualification that provides staff with the essential skills and knowledge in the principles and practices of the VET sector in order to ensure on going compliance in a highly regulated environment. Furthermore this qualification provides staff with the principles of teaching and learning. Whilst it is recognized that regulatory compliance is compulsory the primary aim of the VET sector is education. This mandates that lecturing staff are professionally qualified in pedagogical principles and practices to an appropriate standard. However seven problems have been identified with this qualification (Maj, 2015). The most significant problems were: 
- Insufficient contact hours in the qualification

The nominal contact time for this qualification is 290 hours. However it is possible to complete the qualification in about 40 hours.

'A number of RTOS that deliver this qualification attempt to deliver it in a mode that does not produce quality students - they offer it in a very short time frames and their graduates have little or no knowledge of VET structures or AQTF requirements.'

Furthermore,

'Timeframe for delivery of this qualification of great concern. Some RTOs deliver this qualification online, face-to-face in as little as 3 days. How can anyone deliver this qualification in 3 days and deem people competent? (Council, 2015).

This is problematic because teaching is complex and intellectually demanding. A high standard of teaching cannot be achieved without a good understanding of pedagogical theory. With only 40 hours of contact time the level of learning could at best be superficial.

- Insufficient content relevant to pedagogy

Maj identified seventy five knowledge items in the qualification but only fifteen directly relevant to teaching. According to Maj, "However fifteen knowledge items directly relevant to teaching represent only 20\% of the total TAE knowledge items. The remainder of the TAE is concerned with issues such as: compliance, validation, moderation, mentoring, workplace facilitation, Australian Quality Training Framework (AQTF) etc. These are important topics but arguably the predominant requirement of a lecturer is to facilitate learning." (Maj, 2015). Even with the recommended contact hours the qualification does not include sufficient pedagogical theory.

- Certificate IV Training and Assessment staff with insufficient knowledge of pedagogical theory

The educational qualification pre-requisite to teach the Certificate IV in Training and Assessment is this award. It is possible there to be taught by someone with no further knowledge of pedagogical principles and best practices.

\subsection{Training Packages}

VET sector education is based on training packages which are endorsed standards and qualifications. There are three aspects to them: units of competency which define the required skills and knowledge; qualifications which are a group of competency; assessment guidelines. Training packages define what must be taught but not how. One possible consequence is variation in content depth. In a study by Maj three implementations of one training package were evaluated. He found that all three implementations had been moderated and validated and hence were deemed fully compliant meeting all mandatory requirements, but there was an extremely wide range in both the depth, scope and pedagogical quality to the extent it would be difficult to consider them equivalent (Maj, 2016)

\subsection{Conclusions}

The Mckenzie report determined that the distinguishing feature of high performing educational institutes was the quality of the teacher. 'The experiences of these top school systems suggests that three things matter most: 1) getting the right people to become teachers, 2) developing them into effective instructors and 3) ensuring that the system is able to deliver the best possible instruction for every child.'

Furthermore the McKenzie report states that,

'The quality of the outcomes for any school system is essentially the sum of the quality of the instruction that its teachers delivery.'

And also, 'Ensuring that teachers have that knowledge and capacity is not easy. Delivering excellent instruction requires teachers to develop a highly sophisticated set of skills.' (Company, 2007)

It can be concluded that a highly developed set of skills cannot be acquired from studying the Certificate IV Training and Assessment.

\section{Unit Analysis}

The quality of course material may be evaluated by a taxonomy such as Structured Observation of Learning Outcomes (SOLO) which distinguishes between low order and high order learning outcomes by the categories of: uni-structural, multi-structural, relational and extended abstract (Biggs \& Collis, 1989). The SOLO taxonomy was the evaluation instrument used. A selection of courses from different institutes was evaluated and ranked on a scale of 1 (lowest) to 5 (highest). The analysis consisted or determining if the course material provided 
structured instruction that progressed from simple rote learning (low order) to relational knowledge (high order) (table 1).

Table 1. None of the courses evaluated demonstrated high quality. It was noted that IT courses are strongly vendor based in which course materials are provide by a vendor. However this does not necessarily guarantee the highest quality of course material (McIIwain, 2016)

\begin{tabular}{llll}
\hline Discipline & Level & Vendor based & Overall evaluation \\
\hline IT & Certificate & Substantially vendor based & 2 \\
& Diploma & Substantially vendor based & 2 \\
Engineering trades & Certificate & & 1 \\
Business & Certificate & 2 \\
& Diploma & 2 \\
\hline
\end{tabular}

\section{Discussion}

From extensive surveys it would appear that the Australian VET system provides an exemplar of best practices in educational outcomes. It is highly regulated with numerous checks and balances to help ensure quality outcomes. Furthermore this regulatory environment embeds employer needs and expectations to help ensure student employability. Unlike the Australian university sector lectures in the VET sector must complete the Certificate IV Training and Assessment and use national developed training packages. However, this framework fails to recognize that pedagogical best practices are of paramount importance to educational principles and practices. Furthermore development of the associated skills and knowledge is demanding and time consuming - a standard that the Certificate IV fails to achieve. A preliminary analysis of a range of courses failed to find examples of high quality teaching and learning outcomes based on the SOLO taxonomy. Furthermore in the IT discipline there was prevalence for the extensive use of vendor based curriculum. Vendor based material is not of itself an assurance of quality. Further, more comprehensive evaluations are needed.

\section{References}

Biggs, J., \& Collis, K. (1989). Towards a Model of School-based Curriculum Development and Assessment Using the SOLO Taxonomy. Australian Journal of Education, 33(2), 151-163.

Company, M. (2007). How the world's best-performing schools come out on top. Retrieved from http://mckinseyonsociety.com/how-the-worlds-best-performing-schools-come-out-on-top/

Council, N. Q. (2015). Certificate IV in Training and Assessment. Retrieved from Melbourne, Australia:

iVET. How VET works. Retrieved from http://www.ivet.com.au/a/65.html

Maj, S. P. (2015). Training the Trainer in Australia - A critical analysis. Modern Applied Science, 9(13), $263-270$.

Maj, S. P. (2016). Australian National Training Packages - a critical analysis. Modern Applied Science, 10(11).

McIIwain, J., McIIwain, O., Maj, S. P. (2016). Facilitating Network Technology training in the Australian Vocational Education Sector. Modern Applied Science, 10(11).

NCVER. (2015). Government-funded VET outcomes 2015: infographic.

$\begin{array}{ccccc}\begin{array}{c}\text { Statistics, } \\ \text { http://www.abs.gov.au/ausstats/abs@.nsf/0/FBC2FEEBF38C6DD6CA25773700169C92?opendocument }\end{array} & \text { A. }\end{array}$

\section{Copyrights}

Copyright for this article is retained by the author(s), with first publication rights granted to the journal.

This is an open-access article distributed under the terms and conditions of the Creative Commons Attribution license (http://creativecommons.org/licenses/by/4.0/). 